\title{
Construindo com bits: análise do processo de projeto assistido por computador
}

Building with bits: an analysis of design process aided by the computer

\section{JULIANO CARLOS CECÍLIO BATISTA OLIVEIRA}

Arquiteto urbanista, graduado em Arquitetura e Urbanismo pelo Curso de Arquitetura e Urbanismo da Universidade de Uberaba, mestre em Arquitetura pelo Programa de Pós- Graduação em Arquitetura e Urbanismo da Escola de Engenharia de São Carlos da Universidade de São Paulo, professor do Curso de Arquitetura e Urbanismo da Universidade de Uberaba.

jcoarq@yahoo.com.br

\section{Resumo}

Esta pesquisa investiga as práticas de projeto atualmente utilizadas em escritórios de arquitetura paulistas. Analisa o processo de projeto na arquitetura contemporânea brasileira paulista, diante da crescente informatização da prática arquitetônica. Pesquisas já indicam que o processo de trabalho sofre alterações com a gradual incorporação da informática pelos escritórios, principalmente no momento de desenvolvimento do projeto. Diante disso, esta pesquisa se propõe a investigar os momentos iniciais de tal processo, quando é gestada a idéia e esta começa a se materializar, seja sob a forma de croquis ou de modelos físicos e virtuais. O trabalho começa com uma pesquisa bibliográfica, e se apoia em estudos de casos de escritórios paulistas, através da realização de entrevistas com seus arquitetos e análise de seus projetos. Discute, também através de revisão bibliográfica, a formação de uma nova idéia de sociedade, baseada na informação e numa crescente Cultura Digital - paradigma conhecido por Sociedade da Informação. A pesquisa aborda, ainda, aspectos de Teoria do Projeto, com ênfase em processos de concepção tradicionais e digitais.

Palavras-chave: sociedade da informação; teoria do projeto; processo de projeto; arquitetura contemporânea brasileira; informática aplicada à arquitetura.

\section{Abstract}

This research investigates the design practice currently used in architectural offices in São Paulo state. It analyzes their design process, in a context of an increasing computerization of the architectural practice. The literature in the area already indicates that the workflow has changed with the gradual incorporation of computer resources in the offices, mainly during the design process. The present research investigates the initial phases of such process, when ideas are generated and starts to materialize, either under the form of sketches or physical and virtual models. The work starts with a literature review, followed by a number of case studies of São Paulo offices, through interviews with their architects and the analysis of their design projects. It suggests, also based on the literature review, that a new society is emerging, based on the information and an increasing Digital Culture - a paradigm 
known as Information Society. The research also approaches aspects of Design Theory, with emphasis in traditional and digital processes of design.

Key-words: information society; design theory; design process; Brazilian contemporary architecture; CAD.

\section{Construindo com bits: análise do processo de projeto assistido por computador}

Poucas pessoas percebem que se descortina no panorama arquitetônico um novo paradigma, através da qual entendemos "a arquitetura digital como fonte de possibilidades $e$ não apenas como projeção representacional de imagens", fato "de extrema importância para o avanço teórico e prático da ação projetual, abrindo portas para a interconectividade do corpo, a realidade física e a imaginação" (EICHEMBERG, 2003). No campo da representação e da simulação, agora explorados pelas imagens digitalizadas, mostra-se cada vez mais urgente uma "hibridação entre o pensamento tecno-científico, formalizável, automatizável, e o pensamento figurativo criador" (COUCHOT, 2001, p. 47).

A inserção da informática num campo de trabalho que age ainda sobre práticas seculares deve alterar radicalmente os modos da profissão.

No decorrer da história, estas práticas [de projeto] pouco se transformaram no que se refere ao uso de materiais de trabalho, estando mais sujeitas a transformações ditadas pelas diferentes formas de se entender a arquitetura. Assim, a prática do trabalho tem se mantido a mesma, apesar dos procedimentos e processos terem sofrido alterações à medida que a arquitetura persegue novos objetivos. (PINTO, 2000, p. 6-7)

A realidade da prática projetual tem se transformado rapidamente. É uma mudança que já começou, mas para muitos tem passado despercebida. Silenciosamente, os recursos oferecidos pela informática penetraram nos escritórios, modificando sua rotina de trabalho, a composição de seus funcionários e, principalmente, os processos de projeto.

Independentemente do porte do escritório ou da experiência do profissional, as modificações podem ser notadas, caso seja realizada uma análise criteriosa e despida de preconceitos.

Neste artigo estão as conclusões de uma pesquisa de Mestrado', que buscou encontrar tais alterações no processo de projeto através do estudo e análise das práticas projetuais de jovens arquitetos paulistas. Para isso, analisa não apenas obras de arquitetos, mas 
principalmente seu discurso - não sem antes esclarecer o contexto das modificações pelo qual passa a sociedade contemporânea, inserindo a arquitetura neste momento. Ouvimos como os profissionais encaram seu trabalho, suas atividades cotidianas de projeto, a interação com seus funcionários e principalmente seu modus operandi.

Assim, na primeira parte da pesquisa, buscamos contextualizar o quadro de mudanças, bastante significativas, pelo qual passa a sociedade de uma forma geral. Mudanças influenciadas pela emergência de novas TIC's, capazes de alterar rotinas e conceitos nas mais diversas áreas do conhecimento - Arte, Economia, Ciências Sociais e, inclusive, Arquitetura. Dessa forma, compreendendo a abrangência desse salto paradigmático, nos detivemos sobre suas influências no campo da Arquitetura, de forma mais específica. Era necessário compreender o início da informatização e, principalmente, o estado da Arte da arquitetura brasileira e o da arquitetura paulista contemporânea, em especial.

Concomitantemente a isso, mostrava-se importante um aprofundamento sobre a Teoria do Projeto. Assim, debruçamo-nos sobre a origem do projeto de arquitetura e sua importância para a construção da idéia do Arquiteto e do Projeto. Em seguida, enfocamos a universalização do desenho e a discussão de um momento importante quando se fala em projeto e informática: o Movimento dos Métodos de Projetoii, um período no qual se confiou na capacidade humana de compreensão das necessidades do homem e na sua resolução a partir da atividade projetual apoiada por máquinas. Porém, falar de projeto também significa discutir o poder do desenho como meio para a emergência e reinterpretação das idéias e de suas novas formas, agora produzidas através de recursos da informática. Os tradicionais materiais de trabalho do arquiteto mesclam-se a novos recursos, capazes de influenciá-lo em seu processo de trabalho. Discutimos então o conceito e os mecanismos de funcionamento dos principais programas utilizados pelos arquitetos.

Findo este percurso, estávamos aptos para a análise de um conjunto de dados coletados em diversos escritórios de arquitetura, de tamanhos e configurações diferentes. Analisamos o processo de projeto de cinco escritórios de arquitetura, sendo quatro sediados na cidade de São Paulo e um na cidade de São Carlos, interior do estado de São Paulo. Conversamos com os profissionais do Verbo Arquitetura (da cidade de São Carlos), Andrade Morettin Arquitetos, Estúdio 6 Arquitetos Associados, FGMF Arquitetos Associados e Frentes Arquitetura (todos da cidade de São Paulo)iii. Esses estudos de caso mostram-se uma interessante forma de confrontação do diverso universo teórico analisado com uma realidade pautada pela prática cotidiana, evidenciando, muitas vezes, discursos um tanto distintos. 


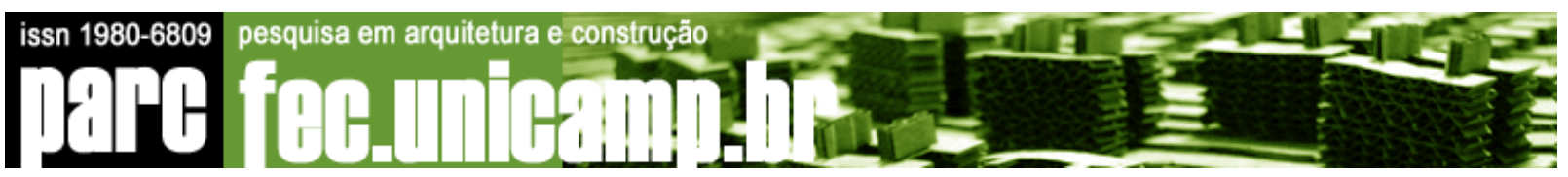

Assim, seguimos para a análise e interpretação de uma série de dados, permitindo-nos apontar algumas questões sobre como tem-se transformado o fazer arquitetura hoje.

\section{Um novo método?}

Um primeiro olhar - uma leitura mais apressada dos dados obtidos em nossa pesquisa poderia levar a acreditar que há, aparentemente, uma perda do método de trabalho. É marcante como os profissionais mais jovens não conseguem esclarecer uma seqüência de seu projetar e não apontam com clareza uma rotina de seu trabalho - ou simplesmente não a têm. Para alguns arquitetos o projeto deve ser reinventado a toda nova obra e o computador parece facilitar isso. Há não muito tempo, dificilmente se encontraria algum profissional que tivesse, por hábito, iniciar um projeto através do desenho técnico realizado com caneta nanquim. Hoje pode-se iniciar o projeto diretamente em programas como o AutoCADß, criando um desenho com precisão milimétrica, pronto a receber cotas e uma prancha para sua plotagem.

Essa abordagem direta e talvez até apressada dos problemas projetuais poderia indicar essa nova flexibilidade ou abertura à experimentação por parte dos profissionais. Contudo, uma leitura mais atenta talvez deixaria de encarar tais acontecimentos como uma perda do método, sugerindo, na verdade, a adaptação a uma nova realidade. A existência de programas que permitem a aceleração das rotinas de trabalho, juntamente com uma maior pressão sobre os prazos de entrega dos projetos, acaba por exigir uma nova postura diante do pensar e fazer arquitetura. Essa é, porém, uma atitude que ainda deve ser conscientemente encarada e amadurecida por cada projetistaiv. Mais ainda, é difícil saber se esta nova arquitetura, fruto desses processos acelerados, é de melhor ou pior qualidade simplesmente por ser produzida mais rapidamente.

O arquiteto César Shundi, do escritório Estúdio 6, comenta sobre essa incerteza diante da rápida alteração dos procedimentos de trabalho:

[...] eu imagino que quando você está num executivo [isto é, desenhando um projeto executivo], num nanquim com não sei quantas folhas $\mathrm{A} 0$, tudo bem, você faz alterações muito menores do que se faz hoje. Mas também acho que, à medida que você ia desenhando, as coisas estavam muito mais resolvidas, efetivamente. Então, há essa tese também, de que apesar de você desenhar nessa velocidade toda, isso leva você a não pensar em todas 


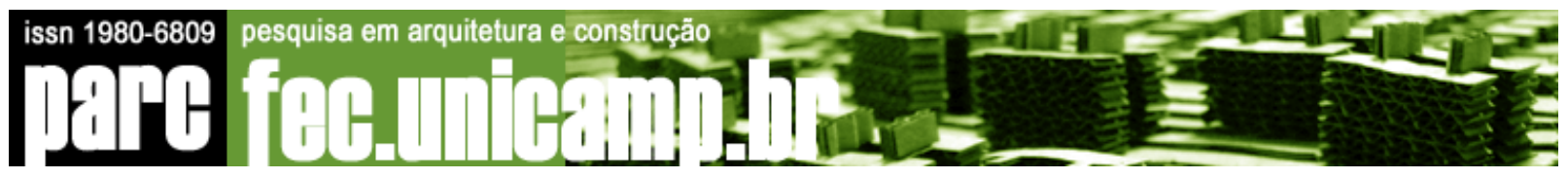

as questões antes de você partir para o desenho executivo mesmo. (SHUNDI, 2006)

É por isso que se pode afirmar que o tempo do projeto é definitivamente outro. Mesmo para profissionais que ainda imaginam projetar de modo tradicional ou analógico, o tempo é diferente, pois o desenvolvimento de seus projetos é, inevitavelmente, digital. A produção de desenhos executivos e de projetos complementares e a distribuição de arquivos para plotagem são exemplos da nova dimensão que as TIC's lançam sobre a atividade do arquiteto. Etapas de um mesmo projeto podem ser executadas por vários profissionais, que agora podem estar em diferentes localizações geográficas e sempre interconectados - numa realidade impensável há alguns anos.

Dessa forma, a prática tem se renovado e deixado muitos arquitetos ainda sem a correta compreensão das possibilidades abertas e muitas vezes por eles já incorporadas.

\section{Maquetes: representação e concepção}

A investigação aponta que o modelo geométrico digital, popularmente conhecido como "maquete eletrônica", tem se aproximado cada vez mais da função antes ocupada pelo croqui e pela maquete tradicional, instrumento útil tanto para a concepção quanto para a representação da idéia projetada.

O início da utilização comercial das "maquetes eletrônicas" ocorreu para a representação de projetos para clientes. Isto é, era um tipo de desenho normalmente produzido com o projeto já resolvido, com o único intuito de facilitar a compreensão, por parte de um público leigo, do que seriam apenas desenhos extremamente abstratos. Aproximava-se assim da maquete tradicional, normalmente feita em madeira ou papel, que encanta os olhos e a imaginação dos futuros usuários dos espaços projetados.

O progressivo barateamento juntamente com o aumento da capacidade de processamento dos computadores permitiu uma utilização mais freqüente da maquete eletrônica dentro da rotina dos escritórios, iniciando uma alteração dos procedimentos de trabalho. Tradicionalmente, programas de desenho em três dimensões, principalmente se acompanhados de programas para renderização, exigiam máquinas poderosas e usuários habilitados.

Ultimamente, tem surgido uma nova realidade. Novos programas para a modelagem em três dimensões de projetos de arquitetura distanciam-se do conceito tradicional da área, de 
criação de imagens hiperreais, para explorarem novas possibilidades. Simular não apenas o traço do arquiteto, mas sua forma de desenhar perspectivas (através de extrusões simples, da criação de planos que juntam-se para formar volumes e da utilização de cores e texturas próximas das obtidas com canetas de desenho ou grafite) tem-se mostrado um recurso valioso para a produção de desenhos que efetivamente auxiliam na concepção do projeto, não se restringindo à sua mera ilustração.

A linguagem simplificada dos programas, aliada à maior fluidez e intimidade em sua utilização, garantiram a inserção da "maquete eletrônica" no início do processo de concepção, permitindo ao arquiteto enxergar e dialogar com as formas imaginadas, assim como o croqui e a maquete tradicional. Mais um meio de trabalho para a emergência e a reinterpretação das idéias, conceito discutido por Menezes (2005) ao tratar das funções do croqui - que aqui se aproximam dos modelos geométricos digitais. Ele destaca como é importante a capacidade do arquiteto de interagir com seus desenhos, usando-os tanto para a criação de soluções impensadas até serem desenhadas quanto para a modificação de propostas já projetadas, esclarecendo que a emergência "refere-se aos pensamentos e idéias que não podiam ter sido planejados ou antecipados antes da execução dos croquis", enquanto que a reinterpretação "refere-se à habilidade de transformar, desenvolver e gerar novas imagens na mente enquanto desenhando." (2005, p. 5)

Em função disso, é importante compreender como a exploração consciente e dedicada dessas novas possibilidades pode enriquecer o processo de criação. Se explorado desde a formação do profissional, as simulações e a realidade virtual podem tornar-se mais uma importante fonte para a exploração do espaço, oferecendo riqueza de pontos de vista que apenas colaborariam para um melhor enfrentamento do problema arquitetônico.

Isso só será possível com, inicialmente, a utilização de programas adequados para tal fim: enquanto se insistir na utilização do AutoCAD® como programa genérico, capaz de resolver a todos os problemas de representação, não se fará grande progresso. Há programas adequados a cada etapa a ser desenvolvida no projeto e o seu intercâmbio é possível e recomendado.

Outro ponto também importante é a formação de professores para o ensino adequado e consciente dessas novas tecnologias, não apenas em aulas de informática, mas por meio da inserção responsável da informática na "sala de pranchetas". Um corpo docente despreparado e fiel apenas a processos tradicionais não corresponde às atuais necessidades 


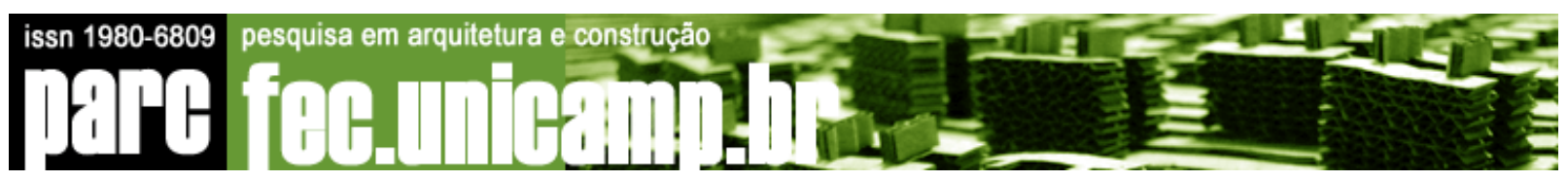

do ensino, pois não mais se questiona a inserção da informática no ensino, mas sim a melhor maneira de conduzir o ensino em meio à informática que nos cerca.

Exemplo claro desse fato, que as entrevistas evidenciam, é a completa ausência, por parte dos projetistas, da utilização de recursos como a construção virtual do edifício ou da construção de maquetes por meio de ferramentas de corte e molde por controle numérico ou de equipamentos de prototipagem rápidav. A Construção Virtual, também chamada de BIM Building Information Modelling, possibilitando, através da modelagem digital do edifício, obter um "desenho inteligente", capaz de informar sobre dados da obra, valores, fornecedores, prazos, indo muito além da mera representação para execução. A utilização de maquetes feitas em "impressoras 3D" ou em máquinas CNC nem sequer foi mencionada pelos arquitetos como uma possibilidade de desenvolvimento de seu projeto - talvez por ser uma tecnologia ainda restrita a outros segmentos da construção ou, pelo menos no Brasil, ainda muito limitada ao mundo acadêmico. Nesse sentido, voltamos a enfatizar a importância da formação do arquiteto já plenamente envolvido com as novas possibilidades de desenvolvimento do projeto arquitetônico.

\section{Representação digital e concepção arquitetônica}

A relação dos profissionais com a informática se dá através da necessidade de representação ${ }^{\text {vi }}$ Não há ainda, entre os escritórios analisados, uma conceituação da arquitetura produzida sob essa nova condição que seja derivada desses novos processos (Foto 01). A título de comparação, poderíamos citar que a criação da estrutura independente de concreto armado e da estrutura metálica colaboraram para o surgimento do Movimento

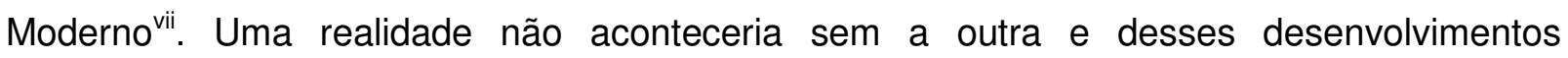
tecnológicos definiu-se uma nova forma de projetar e pensar a arquitetura e a cidade. 

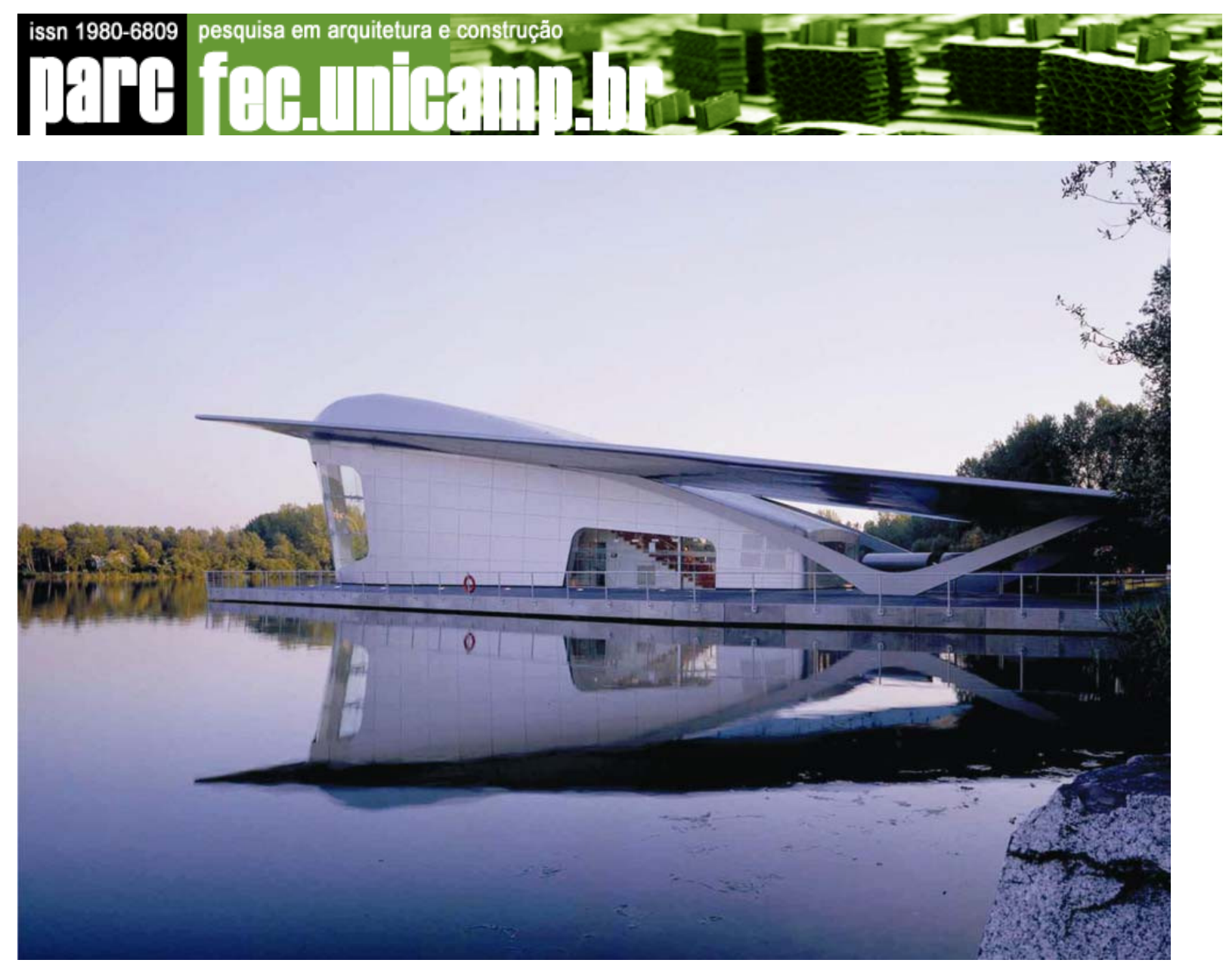

Foto 01: O escritório americano Asymptote, dirigido pelo arquiteto Hani Rashid usa tecnologias computacionais para criar projetos fluidos e contemporâneos, como Hydrapier, construído em Amsterdã. Fonte: ASYMPTOTE, 2007.

É nesse sentido que observamos como ainda é utilizada a informática pelos arquitetos. Seus recursos ainda não foram suficientemente desenvolvidos e aplicados, nos escritórios pesquisados, na criação de espacialidades inovadoras, que não poderiam ser projetadas sem a informática (Fig. 01). Podemos inferir, inclusive, que esta realidade também pertence à absoluta maioria dos escritórios brasileiros. Contudo, esta não é uma crítica negativa, ainda. Diferentemente de países desenvolvidos, a informatização no país acontece em outra velocidade, com recursos muito mais escassos, em um mercado de trabalho com pouca regulamentação profissional e problemas estruturais. 

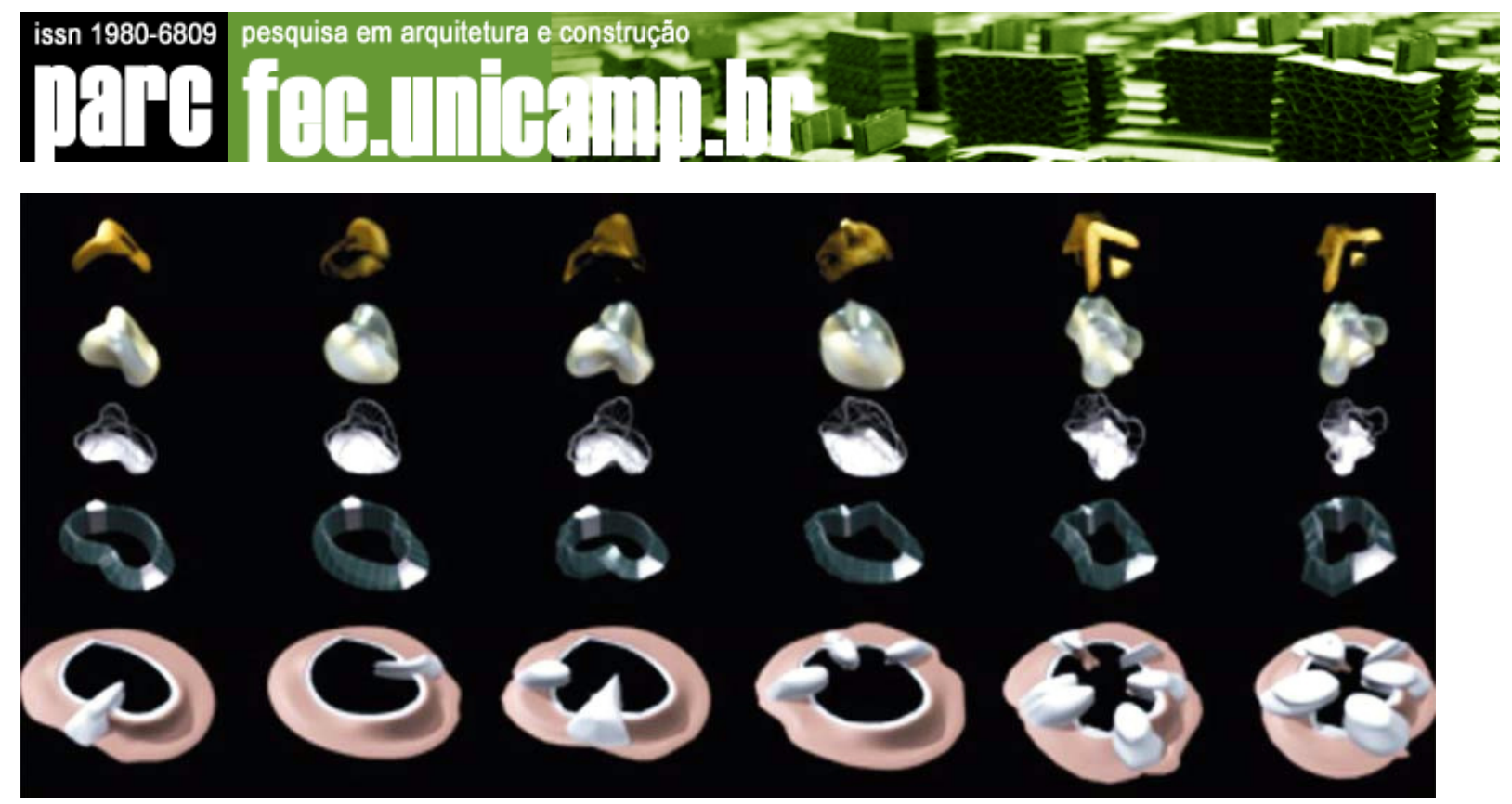

Fig. 01: Algumas variações da conhecida Embriologycal House, do arquiteto americano Grag Lynn, produzidas através do computador. Fonte: FORM, 2007.

Arquitetos como Greg Lynn e Hani Rashid, por exemplo, criam seus projetos a partir das possibilidades ofertadas pela informática, obtendo formas dificilmente imagináveis (e principalmente representáveis) sem tais recursos. Frank Gehry inicia seus projetos de forma completamente tradicional, croquisando e construindo maquetes - para depois se utilizar de recursos da informática, que Ihe são fundamentais (Fig. 02). Sem eles também não seria possível a representação e construção de suas estruturas.

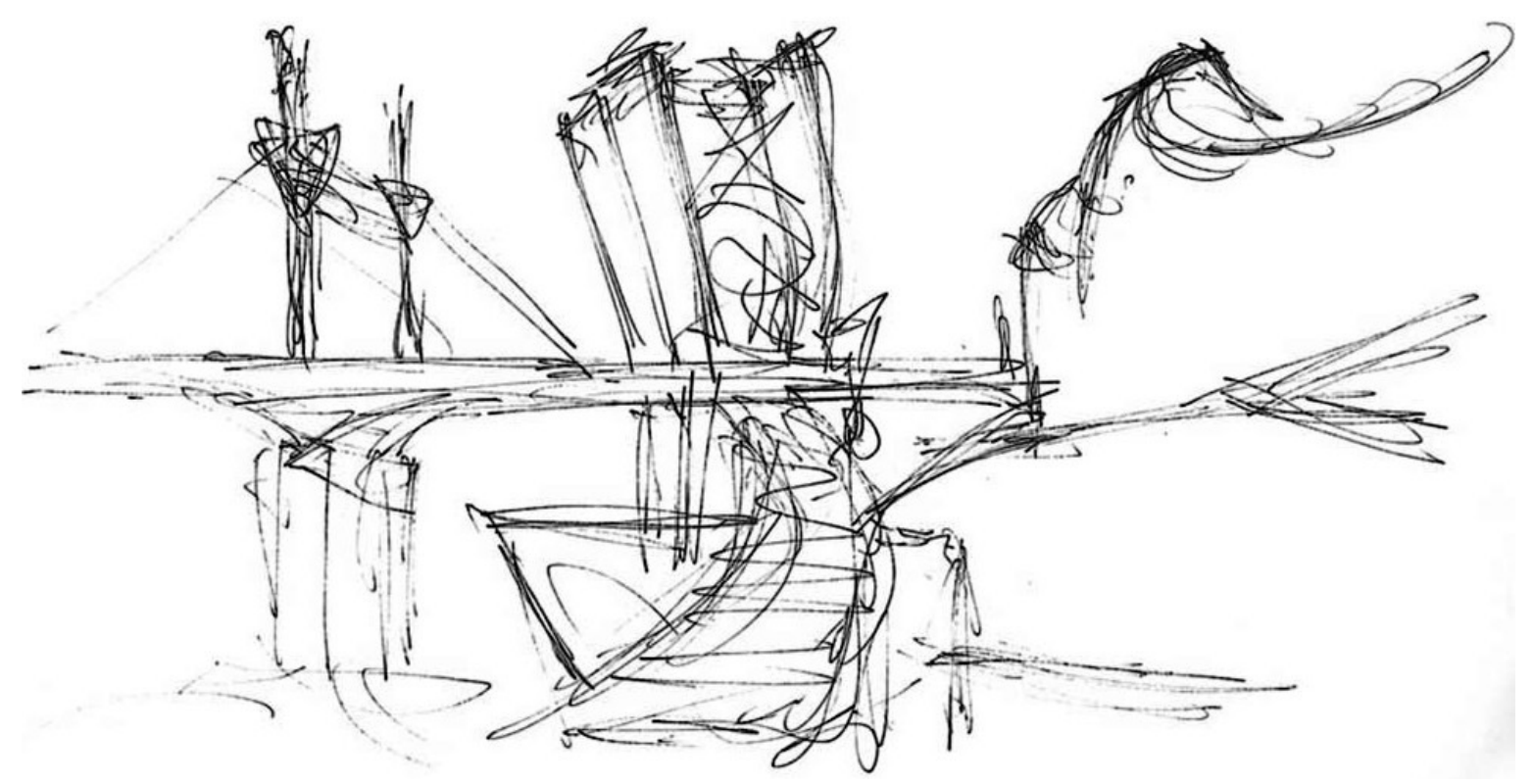


Fig. 02: Croqui da ponte do Museu Guggenhein de Bilbao (Espanha) feito pelo arquiteto Frank O. Gehry. Fonte: CITY OF SOUND, 2007.

O que notamos e esperamos para um futuro próximo, talvez a médio prazo, é um aumento e uma constância na relação entre a arquitetura e a informática. Os recursos e novas possibilidades projetuais oferecidos pelo uso do computador devem contribuir, juntamente com o pensamento do arquiteto (e não apenas servindo ao seu pensamento) no desenvolvimento de novas formas e soluções. Algumas experiências já apresentam resultados bem sucedidos nesse percurso (CELANI, 2003). Esta é, infelizmente, uma realidade distante da grande maioria dos profissionais brasileiros. Muito ainda pode ser feito e aprimorado para a efetiva incorporação dos recursos da informática nos processos de concepção do arquiteto. Compete a nós, pesquisadores e arquitetos, edificarmos esse futuro.

\section{Referências bibliográficas}

ASYMPTOTE. A S Y M P T O T E. Disponível em: <http://www.asymptote.net>. Acesso em 12 de junho de 2007.

BENÉVOLO, Leonardo. História da Arquitetura Moderna. 3aㅡ. ed., $2^{\underline{a}}$ reimp. Trad. Ana M. Goldberger. São Paulo: Perspectiva, 2004. 813 p.

CELANI, Maria Gabriela Caffarena; BERTHO, Beatriz Carro. A prototipagem rápida no processo de produção de maquetes de arquitetura. In: GRAPHICA 2007, 2007, Curitiba. Proceedings of GRAPHICA 2007, 2007.

CELANI, Maria Gabriela Caffarena; GIACAGLIA, Marcelo E.; KOWALTOWSKI, Doris C. C. K. CAD - O lado criativo: duas experiências educacionais visando mudar a forma como estudantes de arquitetura usam o CAD. Revista Pós FAU-USP, São Paulo, SP, v. 1, n. 14, p. 66-78, 2003.

COUCHOT, Edmond. Da representação à simulação: evolução das técnicas e das artes da figuração. In: PARENTE, André (Org.). Imagem X Máquina: a era das tecnologias do virtual. $3^{\underline{a}}$ ed. (1를 reimpressão). São Paulo: 34, 2001.

CITY OF SOUND. Sketches of Gehry's Guggenheim. Disponível em: < http://www.cityofsound.com/blog/images/gugg_bridge1.jpg >. Acesso em 10 de junho de 2007.

EICHEMBERG, André Teruya. Arquitetura Digital: entre a realidade e o esquecimento.

Arquitextos, 032.02, s/p, janeiro de 2003. Disponível em:

<http://www.vitruvius.com.br/arquitextos/arq032/arq032_02.asp> 
FRAMPTON, Kenneth. História crítica da Arquitetura Moderna. Trad. Jefferson Luiz Camargo. $1^{\underline{a}}$ ed. (2 $2^{\underline{a}}$ tiragem). São Paulo: Martins Fontes, 2000. 470 p.

MENEZES, Alexandre Monteiro. O Croqui e a Idéia. In: Seminário Arquitetura e Conceito, 2, 2005, Belo Horizonte. 2 Seminário Arquitetura e Conceito. Belo Horizonte: NPGAU / EAUFMG, CD-ROM.

MONTANER, Josep Maria. Depois do movimento moderno: arquitetura da segunda metade do século XX. Barcelona: Gustavo Gili, 2001. 271 p.

PINTO, Gelson Almeida. Os impactos dos processos infográficos na produção da arquitetura. 1999. 235 p. Tese (Doutorado em Arquitetura) - Faculdade de Arquitetura e Urbanismo, Universidade de São Paulo, São Paulo, 2000.

SHUNDI, César I. Escritório Estúdio 6: prática e projetos [mar. 2006]. Entrevistador: J. C. C. B. Oliveira. São Paulo, 2006. (A entrevista completa está no apêndice do trabalho: Oliveira, Juliano Carlos Cecílio Batista. Construindo com bits: análise do processo de projeto assistido por computador. 2007. Dissertação (Mestrado em Arquitetura e Urbanismo) -Escola de Engenharia de São Carlos, Universidade de São Paulo, São Carlos, 2007.

\footnotetext{
' Cf. Oliveira, Juliano Carlos Cecílio Batista. Construindo com bits: análise do processo de projeto assistido por computador. 2007. Dissertação (Mestrado em Arquitetura e Urbanismo) - Escola de Engenharia de São Carlos, Universidade de São Paulo, São Carlos, 2007

ii Cf. Oliveira, J. C. C. B. O movimento dos métodos de projeto. Vitruvius. Disponível em: <http://www.vitruvius.com.br>. No prelo.

${ }^{i i i}$ A íntegra dessas entrevistas, assim como toda a pesquisa de mestrado encontra-se on-line, para consulta, no site Biblioteca Digital de Teses e Dissertações da USP <http://www.teses.usp.br/>.

iv No capítulo 2 do trabalho, investigamos como o desenho tradicional pode ser importante para o processo de projeto, funcionando como um meio para o amadurecimento das idéias até então restritas à mente do arquiteto. Se há uma nova forma de se pensar, esta deve ser claramente compreendida e posta à prova pelos profissionais.

Celani e Bertho (2007) informam que "A Prototipagem Rápida é uma tecnologia que permite fabricar objetos físicos tridimensionais a partir de arquivos digitais criados em sistema CAD, Computer Aided Design, (projeto auxiliado por computador). Os mesmos dados do desenho do arquivo digital servem para a execução do protótipo [...]" (p. 3). As autoras também lembram que no Brasil o recurso ainda é pouco utilizado por escritórios de arquitetura, ao contrário de escritórios europeus ou americanos (como dos arquitetos Norman Foster ou Frank Gehry).

vi Entenda-se aqui a expressão representação como o desenho de arquitetura (plantas, cortes, perspectivas, etc.) responsável pela possibilidade de visualização da idéia imaginada e, consequentemente, de seu estudo e desenvolvimento durante a criação do projeto.

vii Como ilustração, podemos destacar um breve trecho dos "Cinco pontos da Arquitetura", de Le Corbusier, comentando sobre a planta livre: "O concreto armado traz, para a casa, a planta livre! Os andares não precisam mais ser encaixados uns sobre os outros. Estão livres. Grande economia de volume construído, utilização rigorosa de cada centímetro." (CORBUSIER apud BENÉVOLO, 2004, p. 434). Obviamente, há uma série de outros fatores envolvidos nesta história, que não cabem ser apresentados aqui, mas são muito bem apresentados e discutidos, além de Benévolo, em Frampton (2000) e, de forma resumida, em Montaner (2001, p. 126).
} 